\title{
UNDERSTANDING MEN'S BODY IMAGE IN THE CONTEXT OF THEIR ROMANTIC RELATIONSHIPS
}

\author{
by
}

\section{LAURA BROOKE GOINS}

\author{
A thesis submitted to the \\ Graduate School-Camden \\ Rutgers, The State University of New Jersey \\ in partial fulfillment of the requirements \\ for the degree of Master of Arts \\ Graduate Program in Psychology \\ written under the direction of \\ Charlotte N. Markey, Ph.D. \\ and approved by \\ Luis T. Garcia, Ph.D. \\ Mary Bravo, Ph.D. \\ Camden, New Jersey
}

May 2010 


\begin{abstract}
OF THE THESIS
Understanding Men's Body Image in the Context of Their Romantic Relationships by LAURA BROOKE GOINS
\end{abstract}

Thesis Director:

Charlotte N. Markey, Ph.D.

This study examined men's body image in the context of their romantic relationships. One hundred and four heterosexual romantic dyads completed measures assessing men's body satisfaction, perceptions of men's weight change, relationship length, and sexual intimacy. Researchers also collected measures of men's height and weight. Results indicated that men's body satisfaction was negatively associated with both their actual weight status (BMI) and their perception of their weight gain during the relationship; men were more likely to be satisfied with their bodies when they perceived their partners to be and when their partners actually were satisfied with their bodies. Further analyses revealed that men expressed greater body satisfaction when there was a relatively high degree of sexual intimacy in the relationship. Findings are discussed in terms of the contributions to researchers' and practitioners' understanding of men's body satisfaction. 
Table of Contents

I. Literature Review (pgs. 5-9)

a. Aims of the Present Study (pgs. 9-11)

II. Method (pgs. 12-16)

a. Participants and Procedures (pgs. 12-13)

b. Measures (pgs. 13-16)

III. Results (pgs. 17-18)

IV. Discussion (pgs. 19-24)

a. Limitations (pg. 23)

b. Conclusions and Implications (pgs. 23-24)

V. References (pgs. 25-27)

VI. Appendix (pgs. 31-34)

a. Contour Drawing Rating Scale (pgs. 31-32)

b. Revised Feeding Questionnaire (pg. 33)

c. Sexual Intimacy Measure (pg. 34)

VII. Curriculum Vitae (pgs. 35-36) 
List of Tables and Figures

I. $\quad$ Figure 1: Body Satisfaction Means (pg. 28)

II. Table 1: Correlations among all constructs investigated (pg. 29)

III. Table 2: Simultaneous Regression Analyses Predicting Men's Body

Satisfaction while Controlling for BMI (pg. 30) 


\section{Literature Review}

For most people, romantic relationships are central features of their adult lives.

Existing research has established links between romantic relationship experiences and both physical and psychological health outcomes (Horowitz, McLaughlin, \& White, 1998; Minuchin, 1985, 1988). For example, committed romantic relationships have been associated with better self-reported health status, longevity, and greater overall happiness and satisfaction in life (Tucker, Friedman, Wingard, \& Schwartz, 1996; Markey, Markey \& Gray, 2007). Although studies have connected romantic relationships to these and other health issues, only recently have associations between body image and romantic relationship experiences been investigated. Of these studies examining body image and romantic relationships, many if not all have primarily focused on women's body image and not men's. This trend reflects a common belief that women have a greater tendency to suffer from body image (and often related eating) disorders at much higher rates than do their male counterparts (Striegel-Moore \& Franko, 2004). However, research has provided increasing support to suggest that body dissatisfaction and its psychological consequences may be both as prevalent and damaging among men as among women (Cash and Brown, 1989; Tager, Good, \& Morrison, 2006).

A growing body of research suggests that men and women experience similar societal pressures in terms of their bodies beginning in early childhood (Westmoreland Corson \& Anderson, 2004). Many studies have examined these pressures on women, but more recent research suggests men's body image ideals appear to be changing; men's bodies are presented as both leaner and more muscular in popular culture than in previous decades (Olivardia, Pope, Borowiecki, Cohane, 2004). This trend, in addition to other 
sexualized and unrealistically masculine depictions of men's bodies in popular media, increase the likelihood that men will engage in negative health behaviors (e.g., steroid use and exercise dependence) to alter their body size to conform to societal standards (Olivardia et al., 2004; McCabe \& Ricciardelli, 2004; Varnado-Sullivan, Horton \& Savoy, 2006). Research indicates that these messages, along with societal prescriptions suggesting men's bodies are representative of their masculinity, may be detrimental to men's body image and to their overall health (Filiault, 2007). Although larger social messages have been connected to men's body image, proximal messages from romantic partners remain unexplored. Previous research among women (e.g., Markey \& Markey, 2006; Markey, Markey, Birch, 2004) suggests the relevant role of romantic partners in determining body satisfaction. Thus, understanding variables associated with men's body image, including romantic partners, not only adds to our growing understanding of the factors contributing to men's body image, but extends previous research focusing on women (e.g., Markey \& colleagues, 2004, 2006).

Associations between romantic relationships and women's body image have previously been established (e.g., Markey \& Markey, 2006), yet relationship constructs have not been examined in relation to men's body image. Further, past research does not suggest which romantic relationship qualities (e.g., relationship length, sexual intimacy) may be associated with men's body image. Theory suggests that romantic partners may serve as an important element in an individual's perception of self given that, especially in early adulthood, partners may serve as an individual's most relevant family unit. The Michelangelo Phenomenon (see Drigotas, Rusbult, Wieselquist, \& Whitton, 1999) describes the role of romantic partner as shaping the self through affirmation, or the 
degree to which a partner's perception of the self matches one's own perception of self. This study will extend past research examining romantic relationships and body image by evaluating both partners' perceptions of men's weight, men's bodies, and sexual intimacy in the relationship.

Although a number of studies have looked at body image in the context of romantic relationships, to my knowledge, research has only recently examined body satisfaction and romantic relationships in terms of the perspectives of both partners in the couple (see Markey \& Markey, 2006; Markey, Markey, Birch, 2004). Despite the understudied nature of this area of research, evidence suggests that romantic partners' responses about one another may be particularly important because of the likely association between partners' comments and appearance satisfaction (Tantleff-Dunn \& Thompson, 1995). In fact, a study by Sheets and Ajmere (2005) found that romantic partners' criticism of their partners' body may be of greater significance to men and women than comments from others about their bodies. These findings concur with past research (i.e., Markey, Markey \& Birch, 2004) suggesting that a positive romantic relationship may protect partners from societal pressures regarding their body shape. Interestingly, studies indicate that the actual views of a romantic partner seem to be more important to an individual's body image than his or her perception of their partner's views. In two studies by Markey and colleagues (2004; 2006), women were found to be less satisfied with their bodies than they perceived their romantic partners to be and than their partners actually were. Studies (e.g., Miller, 2001; Tantleff-Dunn \& Thompson, 1995) have also found that among college-age couples, individuals' reports of greater body satisfaction were significantly related to how satisfied they perceived their partners 
to be with their bodies. In addition, individuals' perceptions of their partners' views of their bodies have been linked to romantic relationship satisfaction (Cash et al., 2004). In these and other studies examining romantic relationships and body image, the focus has tended to be women's experiences and has more or less excluded men's reports. In spite of this limited focus, these studies suggest the relevance and potential importance of romantic partners to understanding men's body image development.

In addition to the potential associations among romantic partners' perceptions of each others' bodies, sexuality is another undeniably important aspect of adult romantic relationships that may be associated with body image. In a study by Faith \& Share (1993), body image was found to significantly predict individuals' sexual frequency and was linked to greater sexual experience. A study by Vasilenko, Ram, and Lefkowitz (under review) found that although men tended to feel less satisfied with their bodies over time, they were more satisfied after their first intercourse experience. However, other research indicates that associations among body image and sexuality may not always be positive. Data indicates that the relation between body dissatisfaction and sexuality appears to be reciprocal in nature, such that, a poor body image may negatively affect a sexual relationship and a poor sexual relationship may negatively affect one's body image (Tantleff-Dunn \& Gokee, 2004). This finding suggests that individuals may potentially misinterpret sexual dysfunction as indicative of being physically unattractive or undesirable, an interpretation that likely leads to body image anxiety (Tantleff-Dunn \& Gokee, 2004). Such interpretations may inhibit romantic partners sexually and perhaps lead to avoidance of sexual interaction (Yamamiya et al., 2006). Although research has examined the relation between body image and sexuality (e.g., Sanchez \& Kiefer, 2007; 
Ackard, Kearney-Cooke, Peterson, 2000) and a few studies have examined these variables in the context of romantic relationships (e.g., Tantleff-Dunn \& Gokee, 2004; Weiderman \& Hurst, 1997; Yamamiya, Cash, \& Thompson, 2006), to my knowledge, no other study has examined body image and sexual experiences among exclusive romantic partners.

Aims of the Present Study

The current study extended prior research by using data from both romantic partners and by examining several factors conceptualized as predictors of young men's body satisfaction: actual weight status, perceived weight change during the relationship, and romantic relationship experiences (i.e., relationship length, sexual intimacy). Men's body satisfaction ratings were initially compared to their perceptions of their partners' satisfaction ratings and their partners' actual satisfaction ratings. Consistent with past research examining women (Markey \& Markey, 2006; Markey et al., 2004), hypothesis 1 was that men's own body satisfaction would significantly differ from their perceptions of their partners' satisfaction with their bodies and their partners' actual satisfaction such that men would be more critical of their bodies (i.e., less satisfied) than they perceived their partners to be and than their partners actual were. I next explored whether or not men's perceptions of their partners' satisfaction with their bodies and their partners' actual satisfaction would be associated with men's own body satisfaction. My second hypothesis predicted that, similar to past research among young women, these variables would significantly correlate with men's own body satisfaction. Next, the relation among men's weight (both actual and perceived weight change across their relationship) and their body satisfaction was investigated. Men's actual weight status (BMI) was assessed 
in relation to their body satisfaction. Then, men's and women's perceptions of men's weight change during the relationship were examined in association with men's body satisfaction. Given the known correlation between weight status and body satisfaction, it was hypothesized that men's weight would be negatively associated with their body satisfaction. In other words, I expected men who had lower BMIs would report greater body satisfaction (Hypothesis 3a) and also that when both partners' perceived little weight gain among men, they would again report greater body satisfaction (Hypothesis 3b). Associations among men's body satisfaction and the relationship constructs (i.e., relationship length, sexual intimacy) were next examined. Based on previous research addressing young women (Markey \& Markey, 2006), I hypothesized that relationship length would be negatively associated with men's body satisfaction (Hypothesis 4a). Additionally, because existing research suggests a strong link between sexuality (e.g., sexual desire, function) and body satisfaction, it was expected that sexual intimacy would be positively correlated with men's body image (Hypothesis $4 \mathrm{~b}$ ).

After addressing the first four hypotheses, it was then a goal of the study to explore the ability of the aforementioned constructs to predict men's body satisfaction while controlling for their weight status (BMI). Using regression analyses, I examined whether or not both partners' perceptions of men's weight change during the relationship predicted men's satisfaction with their body. Hypothesis 5 predicted that, even after controlling for BMI, when both men and women perceived that men had gained weight during the relationship, men would report less satisfaction with their bodies. Next, I wanted to determine whether or not men's perceptions of their partners' satisfaction with their body and their partners' actual satisfaction predicted men's body satisfaction while 
controlling for BMI. My sixth hypothesis was that men who perceived their partners to be satisfied with their body and had partners who were actually satisfied with their body would report greater body satisfaction themselves. Finally, while controlling for weight status, the predictive nature of the relationship constructs were each examined. Based on existing research among young women (Markey \& Markey, 2006), it was expected that men who were in relatively longer romantic relationships would report less body satisfaction (Hypothesis 7a). Regarding sexual intimacy, I expected men to report greater body satisfaction when the couple perceives a relatively high level of sexual intimacy in their relationship (Hypothesis $7 \mathrm{~b}$ ). 


\section{Method}

\section{Participants \& Procedures}

One hundred and four heterosexual men participated in the present study as part of a research program examining the influence of romantic partners' on health. This sample was predominantly European-American $(M=76 \%$; African American $=10 \%$, Asian=7\%, Hispanic=7\%), in their mid-20s $(M=25.68)$, and had low to moderate socioeconomic status while having relatively high educational attainment. Participation in the study required that all participants be involved in a current, exclusive romantic relationship that had been established for a minimum of one year. Further, participants' romantic partners were also required to contribute to the study. The study's participating couples reported an average relationship length of 3.88 years and reports of relationship status qualified $40 \%$ as dating, $34 \%$ as cohabitating (i.e., living together), and $26 \%$ as married. APA's ethical standards for the treatment of human participants in research were observed in collecting this data.

Participation in this study was advertised to students of a major northeastern public university through class announcements and campus advertisements. Surrounding communities were notified of the study through newspaper advertisements. In addition, a “snowball sampling" technique was used, which involved participants recommending other couples that might be eligible and interested in participating. Student participants comprised the minority of the sample (14\%) and were compensated with research credit for an Introduction to Psychology course; community members received $\$ 50.00$ as compensation for their contribution to the study. Participants were asked to report to the 
lab setting, where they were provided with general information about the study and then given instructions for completing the surveys addressing relationship and health constructs. Participants were then separated into different rooms to privately complete the questionnaires. Trained research assistants remained with participants throughout the duration of the study (approximately 1.5 hours). Lastly, measurements of participants' height and weight were collected by trained researchers.

\section{Measures}

Participants' body satisfaction was measured using the Contour Drawing Rating Scale (CDRS; Thompson \& Gray, 1995). The scale consists of nine pictorial figures illustrating varying male body sizes. Each figure is labeled with a number, 1-9, where 1 illustrates a very underweight figure and 9 illustrates a very overweight figure. Participants were given the CDRS depicting the body shapes and questions pertaining to their satisfaction with their own body, and their partners were given the CDRS depicting the same body sizes with questions pertaining to their satisfaction with their partners' body. Men were asked to select the figures that represent: (1) what they think they currently look like, (2) what they would like to look like, (3) what they think their romantic partners would like them to look like and (4) what they think their romantic partners think they currently look like. Women were asked to select the figures that represent: (1) what they think their romantic partner looks like and (2) what they think they would like their romantic partner to look like. Each of these questions were used to create discrepancy scores indicating men's (a) own body satisfaction, (b) perception of their female partners' satisfaction with their bodies, and (c) women's actual satisfaction with men's bodies. 
Measurements of participants' own body satisfaction were created by subtracting participants' responses referring to their actual body shape ("Which figure looks most like you?”) from their ideal body shape (“Which figure would you like to look like?”). A discrepancy score was also created to measure participants' perception of their partners' satisfaction with their body by subtracting participants' responses referring to the body shape they thought their partner thought represented their actual body shape ("Which figure do you think your significant other thinks you look like?") from the response indicating the body shape they thought their partner would select as their ideal body shape ("Which figure do you think your significant other would like you to look like?"). Lastly, a measure of partners' actual satisfaction with participants' bodies was created by subtracting women's responses referring to the actual body shape they thought looked like their partner ("Which figure looks like your significant other?") from responses indicating the ideal body shape they would like for their partner ("Which figure would you like your significant other to look like?"). A body satisfaction score of 0 meant that participants' actual and ideal ratings were equal, indicating body satisfaction. If scores yielded a negative number, this suggested participants' actual rating was higher (thus, heavier) than their ideal rating and indicated a desire to be/have their partner be thinner. If scores yielded a positive number, this suggested participants' actual rating was lower (thus, thinner) than their ideal rating and indicated a desire to be/ have their partner be heavier. Past use of this measure has yielded a test-retest reliability of 0.79 (Thompson \& Gray, 1995).

Participants' Body Mass Index (BMI) was used as a measure of weight status. In this study, three measurements of participants' height and weight were collected by 
trained research assistants in a lab setting. These measurements were then averaged to calculate a composite BMI score for participants, with men's average BMI being 27.35. In accordance with the statistics presented by the Centers for Disease Control and Prevention (CDC), the percent of men in this sample who fit the criteria of overweight $(39 \%)$ or obese $(25 \%)$ is similar to national statistics on the prevalence of overweight and obesity for this age group (32\% and 34\%, respectively; CDC, 2008).

Participants' perceptions of their own weight change and their partners' perceptions of their weight change were measured using a revised version the Child Feeding Questionnaire (CFQ; Birch et al., 2001; see Markey, Gomel, \& Markey, 2008). Participants were asked to indicate what they believe their weight status to have been when they began their romantic relationship ("When I first met my partner, I was...") and what they currently believe their weight status to be ("Right now I think I am..."). Partners were also asked to indicate their perceptions of men's weight status at the start of their relationship ("When I first met my partner, he was...") and their current perception of his weight status ("Right now I think my partner is...”). Both partners responded to all items using a five-point Likert scale, where 1 is "markedly underweight" and 5 is "markedly overweight." These items were used to create discrepancy scores indicating the extent to which participants and their romantic partners perceive men's weight to have changed during the course of their relationship. Past use of this measure has yielded reliabilities of .71 and .83 for self and other, respectively. In the current sample, perceptions of men's current weight and weight change during the relationship was consistent across partners, where alpha equaled .74 and .76, respectively. 
A measure of couple's sexual intimacy was created for the purposes of this study using items from three different surveys. A question from the Marital Interactions Scale (Braiker and Kelley, 1979) asking participants to rate sexual intimacy in their relationship (i.e., "How sexually intimate are you with your partner?") was used in this measure. Participants were asked to select a rating, ranging 1-9, where 1 indicates very little sexual intimacy and 9 indicated a lot of sexual intimacy. In addition, one item from the Marital Self-Disclosure Questionnaire (MSDQ; Waring, Holden and Wesley, 1998) was used as part of this measure and asked participants to circle true or false regarding the statement "I tell my significant other how I feel about our sexual relationship." The final item included in this measure is a statement from the Locke-Wallace Scale (Locke \& Wallace, 1959) which asks participants to rate the amount of agreement between themselves and their partners in regard to "sex relations" in their romantic relationships, ranging from always agree to always disagree. These items were standardized and then used to create a single measure of couple's sexual intimacy. In order to take advantage of both partners' responses, composite scores were created to establish "couple" ratings, rather than individual partner ratings. Reliability for this measure yielded a Cronbach's alpha of .78. 


\section{Results}

In order to address Hypothesis 1, analyses were conducted to examine differences among men's body satisfaction, their perceptions of their partners' satisfaction with their body and their partners' actual satisfaction with their body. On average, men were more dissatisfied with their body than they perceived their partners to be with their body and than their partners actually were. Paired samples t-tests were used to compare the means of these variables, revealing that men's own body satisfaction $(M=-.608)$ was significantly different from men's perceptions of their partners' satisfaction with their body $(M=-.324, t(101)=-3.34, p<.01)$ and their partners' actual satisfaction with their body $(M=-.206, t(100)=-4.14, p<.001)$. A comparison of men's perceptions of women's satisfaction $(M=-.324)$ and women's actual satisfaction with men's bodies revealed that these variables were not significantly different from one another among the men in this sample $(M=-.206, t(100)=-1.142, p=.256$, n.s.; See Figure 1).

Correlational analyses were used to examine whether or not men's perceptions of their partners' satisfaction with their body and their partners' actual satisfaction were significantly associated with men's body satisfaction (H2). Results of this analysis indicate a significant, positive relation among these variables. Additionally, the relation between men's actual weight status (i.e., BMI) and their body satisfaction (H3a) and men's and women's perceptions of men's weight change during the relationship in relation to men's body satisfaction $(\mathrm{H} 3 \mathrm{~b})$ were both examined using correlational analyses. As shown in Table 1, men's and women's perception of men's weight change and men's BMI were both significantly correlated with men's satisfaction with their body. Finally, couples' reports of sexual intimacy were found to be significantly 
associated with men's reports of body satisfaction, while relationship length was not (H4).

Simultaneous regression analyses were used to control for men's Body Mass Index (BMI) in predicting their body satisfaction. As shown in Table 2, results indicate that men's perceptions of their weight change during their romantic relationships significantly predicted their satisfaction with their body, whereas women's perceptions of men's weight change marginally predicted men's satisfaction (H5). Men's perceptions of their partners' satisfaction and women's actual satisfaction with men's bodies were both found to significantly predict men's satisfaction with their bodies (H6). Finally, results indicate that couples' sexual intimacy marginally predicted men's body satisfaction, whereas couples' relationship length did not predict men's satisfaction with their body after taking into account BMI (H7). 


\section{Discussion}

Given previous research (e.g., Markey \& Markey, 2006; Tantleff-Dunn \& Thompson, 1995) suggesting the potentially important role romantic partners' have on one another's health and body image, the objectives of the present study were to identify specific factors contributing to body satisfaction among men in committed romantic relationships. Although romantic relationship factors, weight status, relationship length and sexuality have previously been examined in relation to body image, to my knowledge no other study has examined all of these factors among romantic partners with an interest in predicting men's body satisfaction. Consistent with past research among women (e.g., Markey \& Markey, 2006), my first aim was to compare the mean scores of and explore correlations among men's own body satisfaction ratings, their perceptions of their romantic partners' satisfaction with their body and their partners' actual satisfaction ratings. Examined next were associations among men's body satisfaction, their weight status and their weight change during the relationship as perceived by both themselves and their romantic partners. Next, I explored the relation between men's body satisfaction and the relationship constructs explored in this study (i.e., relationship length, sexual intimacy). Finally, the above predictors were examined while controlling for men's actual weight status (i.e., BMI).

Findings from the present study are consistent with those of past reports among young women (e.g., Markey \& Markey, 2006; Markey et al., 2004) suggesting the potential role of romantic partners in body satisfaction. Analyses performed revealed significant differences between men's own body satisfaction and both their perceptions of their partners' satisfaction and their partners' actual satisfaction with their body. Similar 
to the results found in Markey \& Markey (2006) the men in the present study were more critical of their own bodies than they thought their partners were and than their romantic partners actually were. Unlike past findings (i.e., Markey et al., 2004), this study's results indicate that there was no significant difference between men's perceptions of women's satisfaction and women's actual satisfaction with men's body. This result suggests that perhaps men are aware of the discrepancy between their own body satisfaction and their partners' satisfaction with their bodies. Although this difference was not significant, the present findings still support past reports indicating that romantic partners tend to be more content with their partners' body than individuals are with their own body.

In addition to analyzing the differences in reports of body satisfaction, the relations among these variables were also assessed. As in past research (e.g., Markey \& Markey, 2006), men's perceptions of their partners' satisfaction and their partners' actual satisfaction with their body were both significantly associated with men's own body satisfaction. Taken together, these findings indicate that men thought women were less satisfied with their bodies than women actually were. It seems that for the men in the present sample, their perceptions of their own bodies and of their partners' satisfaction with their bodies was a more accurate guide to their body satisfaction than was women's actual satisfaction with their bodies.

Correlational analyses were conducted to examine associations among men's body satisfaction, men's weight status, perceptions' (men's and women's) of men's weight gain, and relationship constructs. Consistent with past research (e.g., Markey et al., 2004) illustrating a link between weight status (BMI) and body satisfaction, the results of this study indicate that men's body satisfaction was significantly associated 
with their current weight status. In a novel aspect of this study, men and women were asked to assess how much men's weight had changed during their romantic relationship. These assessments were then correlated with men's body satisfaction ratings. The results of these analyses indicated that both men's and women's perceptions of men's weight change was significantly related to how satisfied men were with their own bodies, such that men were happier with their bodies when both partners perceived men to have had little weight gain during the relationship. Not surprisingly, partners' are likely happier with one another's appearance when both maintain a healthy and attractive weight status.

Explored next were romantic relationship variables that were expected to be important to men's body image. In contrast to previous research (e.g., Markey et al., 2004) examining women's body image, results indicate that relationship length was not significantly associated with men's body satisfaction. Also explored was the relation between partners' perceptions of sexual intimacy in the relationship and men's own body satisfaction. Consistent with literature suggesting the importance of sexuality to body image (e.g., Tantleff-Dunn \& Gokee, 2004; Weiderman \& Hurst, 1997; Yamamiya et al., 2006), the results of this analysis revealed that men were more satisfied with their bodies when partners perceived relatively high levels of sexual intimacy in the relationship. This result is not surprising, given that research has shown that the relation between body image and sexuality is such that feeling positive about one's body is often associated with more sexual confidence and gratification (Yamamiya et al., 2006). Present findings suggest that among couples who perceive a lot of sexual intimacy in their relationship, men in those relationships tend to feel more desirable and confident with their bodies. 
To be sure that these findings were not driven merely by men's weight status, men's BMI was controlled for in the next set of analyses. Results indicate that for men, their own perceptions of weight change during the relationship significantly predicted how satisfied they were with their body. However, women's perceptions of their weight change only marginally predicted men's body satisfaction. Although correlational analyses suggested that men were more satisfied with their bodies when women perceived them to have had little weight change, this result indicates that perhaps women's perceptions of men's weight change do not matter as much to men's satisfaction as does their own perceptions of their weight change.

I next examined whether or not men's perceptions of their partners' satisfaction with their body predicted their body satisfaction and also whether or not partners' actual satisfaction predicted men's satisfaction with their body. Results indicate that both variables were predictive of men's body satisfaction. Consistent with the correlational findings discussed earlier, these results seem to suggest that men may determine their own body satisfaction based on their perceptions of their partners' satisfaction with their bodies more so than based on their partners' actual satisfaction. This finding is consistent with past reports (i.e., Tantleff-Dunn and colleagues, 1995; 2004) that suggest that individuals' perceptions of their partners' satisfaction are more influential on one's body image than partners' actual satisfaction.

In examining the relationship variables in this study, the present findings suggest that couples' perceptions of sexual intimacy were marginally predictive of how satisfied men were with their bodies. Although sexual intimacy was significantly correlated with men's body satisfaction, this finding suggests that men's weight status may play a more 
important role in their body satisfaction than this relationship variable does alone. This result suggests that men's actual weight status across time in a relationship may be more central to their sexual intimacy than is their feelings about their weight (i.e. body image). Further research could be useful in determining whether or not relationship constructs have a causal relation with men's body satisfaction over time in romantic relationships.

\section{Limitations}

Results from the present study offer new insights into our growing understanding of men's body image. However, there are some limitations that are worth noting. A primary limitation of the study concerns the correlational and cross-sectional design employed. For example, although associations among relationship variables and men's body satisfaction have been identified, the causal nature of these relations cannot conclusively be determined. Further, longitudinal investigations have the potential to extend these findings to more diverse couples and contribute to our understanding of men's body image across time. Additional limitations include the homogeneous nature of this study's sample (i.e., predominantly early 20’s, Euro-American) and a need for additional relationship measures. In particular, the sexual intimacy measure employed is considered to be a limitation given that it consisted of only three items selected from different surveys. Future studies should re-examine associations among men's body image and romantic relationships with more comprehensive relationship, including sexual intimacy, measures.

\section{Conclusions and Implications}


With research suggesting an increasing concern among men regarding the appearance of their bodies (Olivardia et al., 2004) and a willingness to compromise their health to alleviate these concerns (McCabe \& Ricciardelli, 2004), it has become necessary to better understand predictors of these concerns. One previously unexplored predictor is romantic partners. Existing studies have indicated the potential importance of romantic partners in young adults' self-perceptions (e.g., Drigotas et al., 1999), including the establishment of one's body image (e.g., Tantleff-Dunn \& Thompson, 1995). This study extends past research that has focused on women (e.g., Markey \& Markey, 2006) or that has included only one member of the romantic dyad in analyses (e.g., Sheets and Ajmere, 2005) by including both partners in investigating the relation among romantic relationships and men's body satisfaction. Results from this study suggest that romantic partners and specific aspects (i.e., sexual intimacy) of their relationships are associated with men's body dissatisfaction. Similar to past studies examining women (e.g., Markey \& Markey, 2006), the men in the present study were more dissatisfied with their bodies than their romantic partners were. Men may perhaps be misperceiving their partners' satisfaction with their body because of their own insecurities with their appearance. Research indicates that an association between men's appearance and their masculinity has long been established (Filiault, 2007) and many men incorrectly believe their partners desire them to have a different body type (i.e., more muscular) than they have (Olivardia et al., 2004). The findings from this study suggest the need for additional research exploring the extent to which romantic partners may assist in improving men's perceptions of their bodies and in facilitating the development of healthy body images among men. 
References

Ackard, D.M., Kearney-Cooke, A., \& Peterson, C. B. (2000). Effect of body image and self-image on women's sexual behaviors. International Journal of Eating Disorders, 28, 422-429.

Birch, L. L., Fisher, J. O., Grimm-Thomas, K., Markey, C. N., Sawyer, R., \& Johnson, S. L. (2001). Confirmatory factor analysis of the Child Feeding Questionnaire: A measure of parental attitudes, beliefs, and practices about child feeding and obesity proneness. Appetite, 36, 201-210.

Braiker, H.B., \& Kelley, H.H. (1979). Conflict in the development of close relationships. In Burgess, R., \& Houston, T. (Eds.), Social Exchange in Developing Relationships (pp. 135-168). New York: Academic Press.

Cash, T.F., \& Brown, T.A. (1989). Gender and body images: Stereotypes and realities. Sex Roles, 21, 361-373.

Cash, T.F., Theriault, J., \& Annis, N.M. (2004). Body image in an interpersonal context: Adult attachment, fear of intimacy, and social anxiety. Journal of Social and Clinical Psychology, 23, 89-103.

Center for Disease Control (CDC). (2009). Prevalence of overweight, obesity and extreme obesity among adults: United States, trends 1960-62 through 2005-2006. Retrieved June 7, 2009, from http://www.cdc.gov/nchs/data/hestat/overweight/overweight_adult.htm

Drigotas, S. M., Rusbult, C.E., Wieselquist, J. \& Whitton, S.W. (1999). Close partner as sculptor of the ideal self: Behavioral affirmation and the Michelangelo Phenomenon. Journal of Personality and Social Psychology, 77, 293-323.

Faith, M.S., \& Share, M.L. (1993). The role of body image in sexually avoidant behavior. Archives of Sexual Behavior, 22, 345-356.

Filiault, S. M. (2007). Measuring up in the bedroom: Muscle, thinness, and men's sex lives. International Journal of Men's Health, 6, 127-142.

Horowitz, A. V., McLaughlin, J., \& White, H. R. (1998). How the negative and positive aspects of partner relationships affect the mental health of young married people. Journal of Health \& Social Behavior, 39, 124-136.

Locke, H.J., \& Wallace, K.M. (1959). Short marital adjustment and prediction tests: Their reliability and validity. Marriage and Family Living, 21, 251-255.

Markey, C.N., Gomel, J.N., \& Markey, P.M. (2008) Romantic relationships and eating regulation: An investigation of partners' attempts to control each others' eating behaviors. Health Psychology, 13, 422-432.

Markey, C.N., \& Markey, P.M. (2006). Romantic relationships and body satisfaction among young women. Journal of Youth and Adolescence, 35, 256-264.

Markey, C.N., Markey, P.M., \& Birch, L.L. (2004). Understanding women's body satisfaction: The role of husbands. Sex Roles, 51, 209-216.

Markey, C.N., Markey, P.M., \& Gray, H. F. (2007). Romantic relationships and health: An examination of individuals' perceptions of their romantic partners' influences on their health. Sex Roles, 57, 435-445.

McCabe, M. P., \& Ricciardelli, L. A. (2004). Body image dissatisfaction among males across the lifespan: A review of past literature. Journal of Psychosomatic Research, $56,675-685$. 
Miller, D. J. (2001). Weight satisfaction among Black and White couples: The role of perceptions. Eating Disorders, 9, 41-47.

Minuchin, P. (1985). Families and individual development: Provocations from the field of family therapy. Child Development, 56, 289-302.

Minuchin, P. (1988). Relationships within the family: A systems perspective on development. In R. A. Hinde \& J. Stevenson-Hinde (Eds.), Relationships within families: Mutual influences (pp. 7-26). Oxford, England: Clareden Press.

Olivardia, R., Pope, H. G., Borowiecki, J. J., \& Cohane, G. H. (2004). Biceps and body image: The relationship between muscularity and self-esteem, depression, and eating disorder symptoms. Psychology of Men and Masculinity, 5, 112-120.

Sanchez, D.T., \& Kiefer, A.K. (2007). Body concerns in and out of the bedroom: Implications for sexual pleasure and problems. Archives of Sexual Behavior, 36, 808-820.

Sheets, V., \& Ajmere, K. (2005). Are romantic partners a source of college students' weight concern? Eating Behaviors, 6, 1-9.

Striegel-Moore, R. H., \& Franko, D. L. (2004). Body image issues among girls and women. In T. F. Cash, \& T. Pruzinsky, Body image: A handbook of theory, research, and clinical practice (pp. 183-191). New York: The Guilford Press.

Tager, D., Good, G., \& Morrison, J.B. (2006). Our bodies, ourselves revisited: Male body image and psychological well-being. International Journal of Men's Heath, 5, 228-237.

Tantleff-Dunn, S., \& Gokee, J. L. (2004). Interpersonal influences on body image development. In T. F. Cash, \& T. Pruzinsky, Body image: A handbook of theory, research, and clinical practice (pp. 108-116). New York: The Guilford Press.

Tantleff-Dunn, S., \& Thompson, K.J. (1995). Romantic partners and body image disturbance: Further evidence for the role of perceived-actual disparities. Sex Roles, 33, 589-605.

Thompson, M.A., \& Gray, J.J (1995). Development and validation of a new body image assessment scale. Journal of Personality Assessment, 64, 258-269.

Tucker, J. S., Friedman, H. S., Wingard, D. L., \& Schwartz, J. E. (1996). Marital history at midlife as a predictor of longevity: Alternative explanations to the protective effect of marriage. Health Psychology, 15, 94-101.

Varnado-Sullivan, P. J., Horton, R., \& Savoy, S. (2006). Differences for gender, weight and exercise in body image disturbance and eating disorder symptoms. Eating and Weight Disorders, 11, 118-125.

Vasilenko, S., Ram, N., \& Lefkowitz, E. (under review). Body Image and First Sexual Intercourse in Late Adolescence.

Waring, E. M., Holden, R. R., \& Wesley, S. (1998). Development of the Marital SelfDisclosure Questionnaire (MSDQ). Journal of Clinical Psychology, 54, 817-824.

Westmoreland Corson, P., \& Anderson, A. E. (2004). Body issues among boys and men. In T. F. Cash, \& T. Pruzinsky, Body image: A handbook of theory, research, and clinical practice (pp. 192-199). New York: The Guilford Press.

Wiederman, M.W., \& Hurst, S.R. (1997). Physical attractiveness, body image, and women's sexual self-schema. Psychology of Women Quarterly, 21, 567-580. 
Yamamiya, Y., Cash, T.F., \& Thompson, K.J. (2006). Sexual experiences among college women: The differential effects of general versus contextual body images on sexuality. Sex Roles, 55, 421-427. 
Figure 1

Body Satisfaction Means

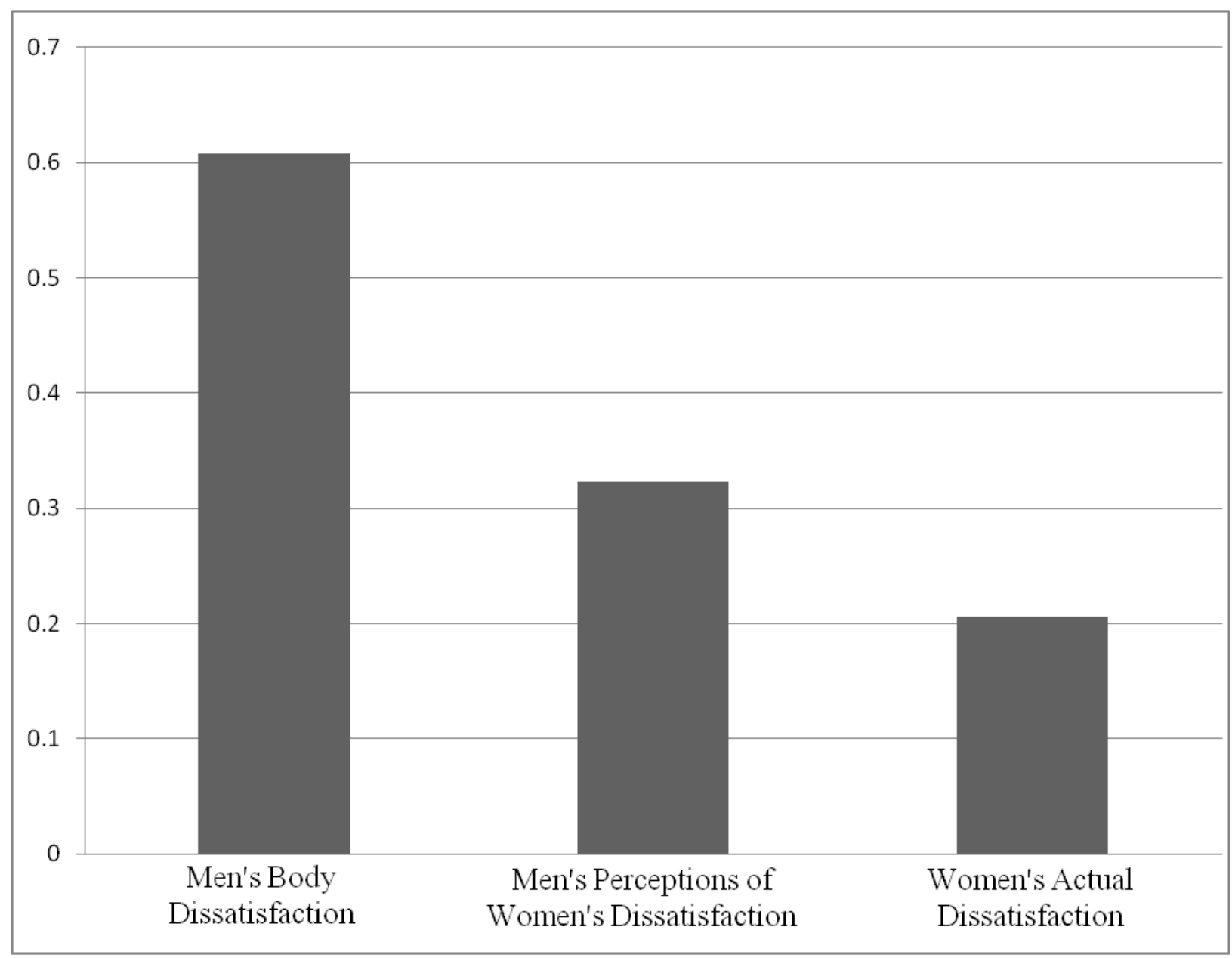


Table 1

Correlations among all constructs investigated

\begin{tabular}{|c|c|c|c|c|c|c|c|}
\hline & 1. & 2. & 3. & 4. & 5. & 6. & 7. \\
\hline $\begin{array}{l}\text { 1. Men's Body } \\
\text { Satisfaction }\end{array}$ & - & & & & & & \\
\hline 2. $\mathrm{BMI}$ & $-.63 * *$ & & & & & & \\
\hline $\begin{array}{l}\text { 3. Men's Perception of } \\
\text { Wgt Change }\end{array}$ & $-.49 * *$ & $.25^{*}$ & & & & & \\
\hline $\begin{array}{l}\text { 4. Women's } \\
\text { Perception of Wgt } \\
\text { Change }\end{array}$ & $-.24 *$ & $.18+$ & $.23^{*}$ & & & & \\
\hline $\begin{array}{l}\text { 5. Men's Perception of } \\
\text { Women's Satisfaction }\end{array}$ & $.75^{* *}$ & $-.48^{* *}$ & $-.39 * *$ & $-.19+$ & & & \\
\hline $\begin{array}{l}\text { 6. Women's Actual } \\
\text { Satisfaction }\end{array}$ & $.66^{* *}$ & $-.53 * *$ & $-.35 * *$ & $-.29 * *$ & $.66^{* *}$ & & \\
\hline 7. Relationship Length & -.14 & $.17+$ & $.22 *$ & .12 & $-.21 *$ & -.11 & \\
\hline 8. Sexual Intimacy & $.26^{*}$ & $-.18+$ & $-.31 * *$ & .14 & $.26^{*}$ & .12 & $-.30 * *$ \\
\hline
\end{tabular}


Table 2

Simultaneous Regression Analyses Predicting Men's Body Satisfaction while Controlling for $B M I$

\begin{tabular}{|c|c|c|c|}
\hline & B & SE B & $\beta$ \\
\hline Men's BMI & -.109 & .014 & $-.552 * *$ \\
\hline \multicolumn{4}{|l|}{ Men's Perception of Their Weight } \\
\hline Change & -.766 & .159 & $-.347 * *$ \\
\hline Men's BMI & -.122 & .015 & $-.611 * *$ \\
\hline \multicolumn{4}{|l|}{ Women's Perception of Men's Weight } \\
\hline Change & -.293 & .172 & $-.133+$ \\
\hline Men's BMI & -.071 & .013 & $-.359 * *$ \\
\hline \multicolumn{4}{|l|}{ Men's Perception of Women's } \\
\hline Satisfaction with Their Body & .556 & .065 & $.575^{* *}$ \\
\hline Men's BMI & -.079 & .016 & $-.398 * *$ \\
\hline \multicolumn{4}{|l|}{ Women's Actual Satisfaction with } \\
\hline Men's Body & .492 & .088 & $.448 * *$ \\
\hline Men's BMI & -.125 & .016 & $-.629 * *$ \\
\hline Relationship Length & -.015 & .044 & -.027 \\
\hline Men's BMI & -.121 & .016 & $-.616 * *$ \\
\hline Couple's Perception of Sexual Intimacy & .038 & .021 & $.139+$ \\
\hline
\end{tabular}




\section{Appendix: Measures}

Measure 1:

Contour Drawing Rating Scale (Thompson \& Gray, 1995)

Men: For the following questions, please look at the below pictures. To answer the questions, circle the number of the figure that is your answer.

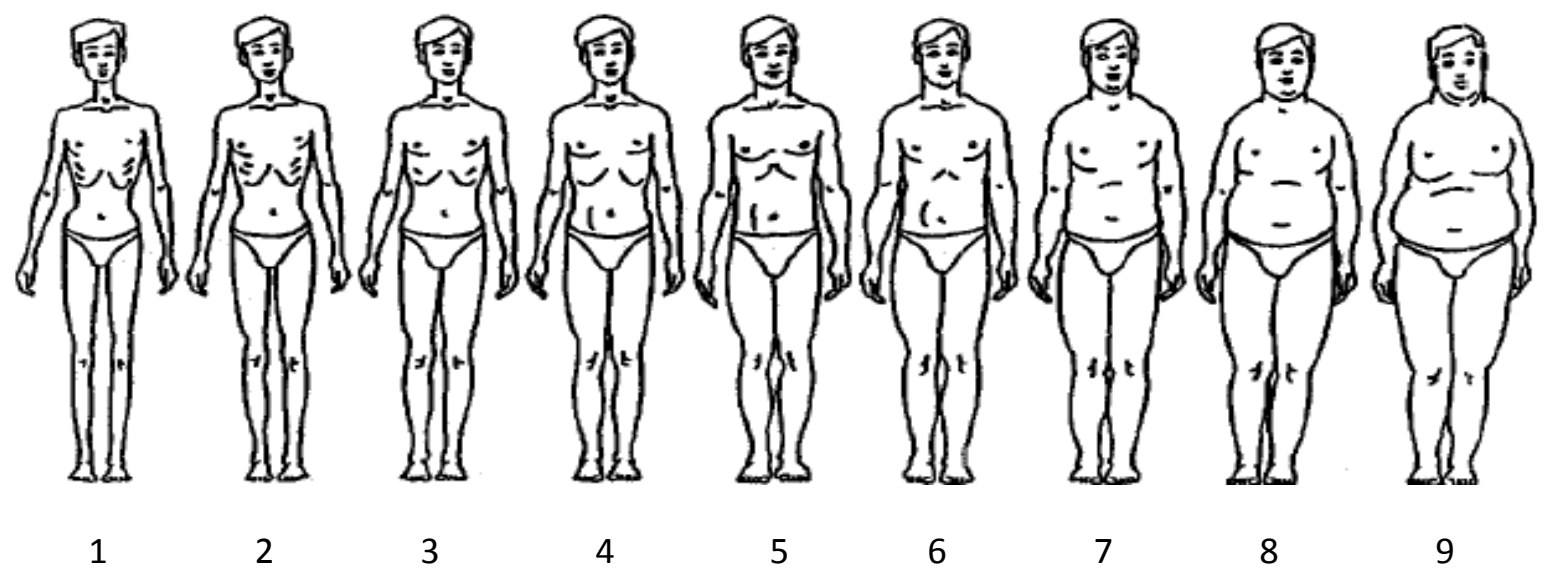

1) Which figure looks most like you?

$\begin{array}{lllllllll}1 & 2 & 3 & 4 & 5 & 6 & 7 & 8 & 9\end{array}$

2) Which figure would you like to look like?

$\begin{array}{lllllllll}1 & 2 & 3 & 4 & 5 & 6 & 7 & 8 & 9\end{array}$

3) Which figure do you think your partner would like you to look like?

$\begin{array}{lllllllll}1 & 2 & 3 & 4 & 5 & 6 & 7 & 8 & 9\end{array}$

4) Which figure do you think your partner thinks you look like?

$\begin{array}{lllllllll}1 & 2 & 3 & 4 & 5 & 6 & 7 & 8 & 9\end{array}$


Women: For the following questions, please look at the below pictures. To answer the questions, circle the number of the figure that is your answer.

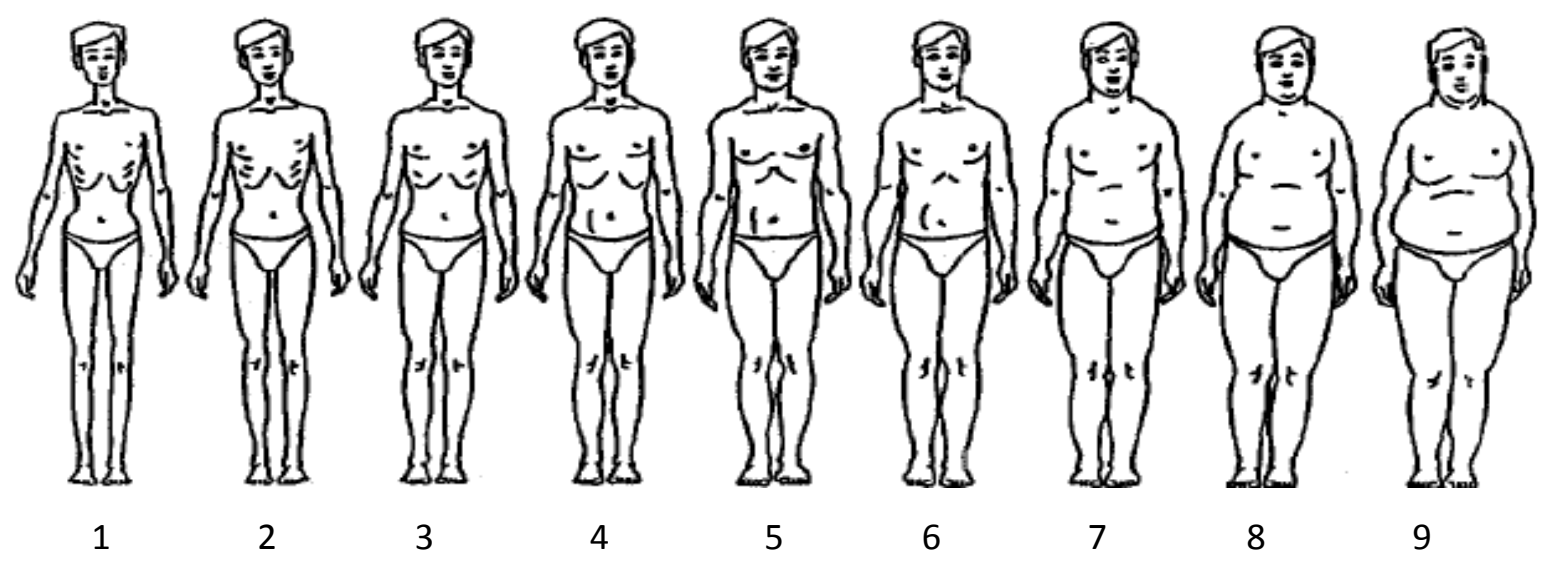

1) Which figure looks most like your partner?

$\begin{array}{lllllllll}1 & 2 & 3 & 4 & 5 & 6 & 7 & 8 & 9\end{array}$

2) Which figure would you like your partner to look like?

$\begin{array}{lllllllll}1 & 2 & 3 & 4 & 5 & 6 & 7 & 8 & 9\end{array}$

3) My partner thinks he looks like picture number:

$\begin{array}{lllllllll}1 & 2 & 3 & 4 & 5 & 6 & 7 & 8 & 9\end{array}$


Measure 2:

Revised Feeding Questionnaire (Birch et al., 2001)

Please circle your response to each question.

\begin{tabular}{|l|c|c|c|c|c|}
\hline $\begin{array}{l}\text { 1) When I first met } \\
\text { my partner, he/she was }\end{array}$ & $\begin{array}{c}\text { markedly } \\
\text { underweight }\end{array}$ & underweight & normal & overweight & $\begin{array}{c}\text { markedly } \\
\text { overweight }\end{array}$ \\
\hline $\begin{array}{l}\text { 2) Right now, I think } \\
\text { that my partner is } \\
\text { markedly } \\
\text { underweight }\end{array}$ & underweight & normal & overweight & $\begin{array}{c}\text { markedly } \\
\text { overweight }\end{array}$ \\
\hline $\begin{array}{l}\text { 3) When I first met my } \\
\text { partner, I WAS }\end{array}$ & $\begin{array}{c}\text { markedly } \\
\text { underweight }\end{array}$ & underweight & normal & overweight & $\begin{array}{c}\text { markedly } \\
\text { overweight }\end{array}$ \\
\hline $\begin{array}{l}\text { 4) Right now, I think } \\
\text { that I AM }\end{array}$ & $\begin{array}{c}\text { markedly } \\
\text { underweight }\end{array}$ & underweight & normal & overweight & $\begin{array}{c}\text { markedly } \\
\text { overweight }\end{array}$ \\
\hline
\end{tabular}


Measure 3:

Sexual Intimacy Measure

Participants were asked the following three questions:

_ "How sexually intimate are you with your partner?"

- Participants were asked to select a rating, ranging 1-9, where 1 indicates very little sexual intimacy and 9 indicated a lot of sexual intimacy.

- (Relationships Questionnaire; Braiker \& Kelly, 1979)

— “I tell my significant other how I feel about our sexual relationship"

- Participants were asked to circle true or false regarding the above statement.

- $\quad$ (Marital Self-Disclosure Questionnaire; Waring, Holding and Wesley, 1998)

- "State the approximate extent of agreement or disagreement between you and your partner on sex relations"

- Participants were asked to rate their answer to the above statement on a 5 point Likert scale, ranging from always agree to always disagree.

- (Locke-Wallace Scale; Locke \& Wallace, 1959) 


\section{Curriculum Vitae}

\section{Laura Brooke Goins}

\section{Education:}

B.A., English and Psychology, Rutgers University-Camden, May 2008, Cum Laude

M.A., Psychology, Rutgers University-Camden, May 2010, Summa Cum Laude

Thesis: Understanding Men's Body Image in the Context of Their Romantic Relationships

\section{Publications and Presentations:}

Peer-Reviewed Publications:

Garcia, L., Cavalie, C., Goins, L., King E. (2008). Enjoyment of sexual activities and attributions of enjoyment to the other gender. Canadian Journal of Human Sexuality, 17 (4), 173-182.

Manuscripts:

Goins, L. B. \& Markey, C. N. (2009). Understanding Men's Body Image in the Context of Romantic Relationships. Manuscript in preparation.

\section{Presentations:}

Goins, L. \& Markey, C. M. (2009, February). Associations among Body Image, Relationship Experiences, and Sexual Intimacy within Romantic Couples. Poster presented at the $10^{\text {th }}$ annual meeting of the Society for Personality and Social Psychology, Tampa, Florida.

Goins, L. \& Garcia, L. (2009, November). Gender and Gender Role Differences in Perceptions of Sexual Activities. Paper presented at the annual meeting of the Society for the Scientific Study of Sexuality, Puerto Vallarta, Mexico.

Goins, L. \& Markey, C. (2010, March). Understanding Emerging Adult Men's Body Image in the Context of Their Romantic Relationships. Presented at the biannual meeting of the Society for Research on Adolescence, Philadelphia, PA.

Markey, C., Markey, P., Goins, L. (2010, March). Late Adolescent Boys' and Girls' Responses to a Media Presentation of Idealized Female Beauty. Presented at the biannual meeting for the Society for Research on Adolescence, Philadelphia, PA.

Goins, L., Garcia, L., Krisch, S., Barger, J. (2010, November). How Individuals Perceive Sexual Activities. Submitted to be presented at the annual meeting of the Society for the Scientific Study of Sexuality, Las Vegas, Nevada.

\section{Research Positions:}

Sexual Activities and Attributions of Enjoyment Study, Rutgers University-Camden, Principal Investigator: Luis T. Garcia, Ph.D. Undergraduate Research Assistant January 2007-August 2008 
Examination of Reality Television Viewing and Interest in Cosmetic Surgery Study, Rutgers

University-Camden, Principal Investigator: Charlotte N. Markey, Ph.D.

Undergraduate Research Assistant January 2008-August 2008

Gender Role Differences in Perceptions of Sexual Activities Study, Rutgers University-Camden, Principal Investigator: Laura B. Goins, B.A.

Research Coordinator Fall 2008 - Present

Women's Menstrual Cycles \& Body Image Study, Rutgers University-Camden, Principal Investigator: Charlotte N. Markey, Ph.D.

Research Coordinator June 2009 - Present

Graduate Research Assistant June 2009 - Present

Parenting, Eating and Obesity Prevention Study, Rutgers University-Camden, Principal Investigator: Charlotte N. Markey, Ph.D.

Research Coordinator

August 2009 - Present

Graduate Research Assistant June 2009-Present

How Individuals Perceive Sexual Activities, Rutgers University-Camden, Principal Investigator: Laura B. Goins, M.A.

Research Coordinator

January 2010-Present 